\title{
Prevalence of gastrointestinal helminthes of donkeys and mules in and around Bahir Dar, Ethiopia
}

Bewketu Takele $e^{1}$ and Endalkachew Nibret ${ }^{2 *}$

${ }^{I}$ Department of Biology, College of Natural and Computational Science, Debre Markos

University, P.O.Box 269, Debre Markos

${ }^{2}$ Department of Biology, Science College, Bahir Dar University, P.O.Box 79, Bahir Dar, Ethiopia

*Corresponding author:

\section{Abstract}

This study was conducted from October, 2010 to April, 2011 in and around Bahir Dar to identify the major gastrointestinal helminthes of donkeys and mules, to estimate prevalence of these parasites and their burden on equines. A total of 384 faecal samples (212 donkeys and 172 mules) were collected randomly for qualitative and quantitative faecal analyses. The overall prevalence of different parasites was found to be $88.21 \%$ in donkeys and $77.91 \%$ in mules. In the study area, $94.1 \%$ of donkeys and $84.33 \%$ of mules harbored two or more types of parasites (mixed infection). The parasites encountered in both donkeys and mules in the study period were strongyles species (65.09\% and 66.28\%), Trichostrongylus axei (42.45\% and 31.97\%), Triodontophorus spp. (36.32\% and 33.72\%), Trichonema spp.(34.91\% and $37.79 \%$ ), Parascaris equorum (13.68\% and 10.46\%), Dictyocaulus arnfieldi (22.17\% and 8.14\%), Anoplocephala (23.12\% and 16.86\%) and Fasciola spp.(17.92\% and $13.95 \%)$, respectively. The prevalence of all identified parasites were statistically significant $(\mathrm{p}<0.05)$ between female and male donkeys. The prevalence of strongyles, T. axei, Triodontophorus, Trichonema, and $P$. equorum was statistically significant $(\mathrm{p}<0.05)$ among age groups of donkeys, but Anoplocephala and Fasciola was not. In mules, the prevalence of strongyles, Triodontophorus and Trichonema was statistically significant ( $\mathrm{p}<0.05$ ), but the prevalence of $T$. axei, P. equorum, D. arnfieldi, Anoplocephala, and Fasciola was not. The body condition score was negatively correlated $(\mathrm{r}=-0.664$ for donkeys and $\mathrm{r}=-0.637$ for mules, respectively) with total eggs per gram of faeces (EPG). The findings of the present study indicated a high prevalence of helminthic parasites compromising the health and welfare of equines. Sustainable prevention and control methods should be developed to prevent the burden of gastrointestinal helminthes of equines in and around Bahir Dar.

Key words: Bahir Dar, donkeys, Ethiopia, gastrointestinal helminthes, mules, prevalence

http://dx.doi.org/10.4314/evj.v17i1.2 


\section{Introduction}

Ethiopia, located in Eastern Africa, is predominantly an agricultural nation. The country has diverse agro-ecological zones, which contributed to the evolution of different agricultural production systems. Animal production is practiced in all ecological zones of the country (Azage Tegegne and Crawford, 2000).

The equine population of the world is 98.3 million (40 million donkeys, 15 million mules, 43.3 million horses). In the distribution pattern, $98 \%$ of all donkeys, $97 \%$ of all mules, and $60 \%$ of all horses are found in developing countries (Wilson, 2002).The number of equines in Africa is in the range of 17.6 million, comprising 11.6 million donkeys, 2.3 million mules and 3.7 million horses (Fielding, 1991). The equine population in Ethiopia is estimated to be 8.4 million $(2.75$ million horses, 5.02 million donkeys, and 0.63 million mules) (Wilson, 1991). In Amhara region, the equine population is estimated to be 1.9 million (www.esgpip.org/Amhara.htm). Equids - donkeys, mules and horses- play an important role as working animals in many parts of the world, employed for packing, riding, carting and ploughing (Feseha Gebreab et al., 1991). Equines power in both rural and urban transport system is cheap and viable, providing the best alternative in places where the road network is insufficiently developed, and the terrain is rugged and mountainous, and in the cities where narrow streets prevent easy delivery of merchandise (Feseha Gebreab et al., 1991).

Although equines are often described as hardy and resistant animals, they do suffer from a number of health problems (Svendsen, 1986; Marquardt et al., 2000). Parasitic diseases have an economic impact on donkeys and mules as they cause loss through lowered fertility, reduced work capacity and increased treatment cost (Krecek et al., 1989). These diseases are also serious to the welfare of donkeys and mules, causing pain in affected animals (Fikru Regassa et al., 2005). Infections of equines with gastrointestinal parasites are recorded from most countries of Africa and few parts of Ethiopia. In Ethiopia, few studies were done in central and eastern parts of the country (Feseha Gebreab, 1998; Ayele Gizachew et al., 2006). Previous studies and observations conducted have pinpointed helminthic parasites as being a major health hazard, limiting the overall performance of equines. Among the helminthes, strongyles (large and small strongyles), Trichostrongylus axei, Triodontophorus species, Trichonema species, Parascaris equorum, Anoplocephala species, Dictyocaulus arnfieldi, and Fasciola species are the most known devastating parasites of equines (Pandit et al., 2008). 
To our knowledge, a previous report on helminthosis of equines (mule and donkeys) in and around Bahir Dar has not been available. The present study was therefore undertaken with primary objective of estimating the prevalence of helminthosis in equines of Bahir Dar and its surroundings.

\section{Materials and Methods}

The study area

Bahir Dar is located at the geographic co-ordinates of $11^{\circ} 38^{\prime}$ North latitudes and $37^{\circ} 15^{\prime}$ East longitudes. In relative terms, Bahir Dar city is located at the distance of $567 \mathrm{~km}$ north of Addis Ababa. The area is known for its water resources, Lake Tana and Blue Nile River. The core city has an estimated area of 16000 hectares (http://campus.Iss.nl).

Study animals and protocol

Fresh faecal samples were taken from 384 equines. Among 384 equines; 172 were mules (80 males and 92 females) and 212 were donkeys (112 males and 100 females). Equines were selected by simple random method in and around Bahir Dar and faecal specimens were taken and subjected to quantitative and qualitative coprological examination to identify the major gastrointestinal helminthes involved. The cart-men and farmers were informed on the importance of the study. The age of the selected donkeys and mules was determined from birth records of owners and by dentition (Crane and Svendsen, 1997). Body condition score (BCS) was subjectively estimated based on the guides published by Svendsen (1997). Accordingly, donkeys were grouped into three age categories: donkeys from 1-2 years of age were classified as young $(\mathrm{n}=33)$; 3-10 years were considered as adult $(\mathrm{n}=74)$; and those beyond 10 years were classified as old $(\mathrm{n}=105)$ whereas mules from 2-10 years were considered as adult $(n=67)$ and above 10 years were considered as old $(n=105)$. These age classes were based on age of first work, productive age and the life span of Ethiopian donkeys (Svendsen, 1997; Yosef Shiferaw et al., 2001). Regarding BCS, the studied animals were grouped as poor, medium, and good.

Sampling technique

Faecal samples were taken directly from the rectum or from the ground with strict sanitation when the animals were seen defecating and placed in universal bottles. 
Each sample was labeled with animal identification (sex, age, BCS and owner's name) and then brought to Bahir Dar Regional veterinary laboratory. Samples were kept in refrigerator at $4^{\circ} \mathrm{C}$ to be examined for coproscopic examination. Sodium chloride solution was used as flotation fluid for this study. Modified McMaster, sedimentation and flotation methods were used to identify and count eggs of helminthic parasites (Soulsby, 1982; Urquhart et al., 1996). Severity of infection as obtained from the number of eggs per gram of faeces was determined according to Soulsby (1982) as follows: less than or equal to 500 eggs/gram of faeces regarded as mild infection; 800-1000 eggs /gram of faeces as moderate infection; and 1500$2000 \mathrm{eggs} /$ gram of faeces as severe infection.

Sample size determination

The study design was cross-sectional and an expected prevalence of $50 \%$ for gastrointestinal helminthes was taken into consideration for sample size determination as there was no previous report on the prevalence of the parasites in the study area. With $95 \%$ confidence level and 5\% absolute precision, the required sample size was calculated by the following formula (Thrusfield, 1995) and as per the calculation, 384 equines (172 mules and 212 donkeys) were included in study.

$$
\mathrm{n}=\mathrm{Z}^{2} \times \mathrm{P}(1-\mathrm{P}) / \mathrm{d}^{2} \text {, }
$$

Where $\mathrm{n}=$ the required sample size, $\mathrm{Z}=$ Confidence level (regular value $=1.96$ ), $\mathrm{P}=$ expected prevalence $(50 \%)$ and, $\mathrm{d}=$ desired absolute precision $(0.05)$

Preparation of faeces for microscopic examination

Sedimentation technique

A simple gravitational sedimentation technique and centrifugation were used to concentrate the helminth eggs as described by Hendrix (1998). Using a tongue depressor, about 2 gram of faeces was mixed with distilled water in a $250 \mathrm{ml}$ conical plastic beaker. The mixture was allowed to sit undisturbed for one hour on a table. The supernatant in the top of the beaker was poured-off without disturbing the sediment at the bottom. Using pasture pipette, small amount of the middle layer of sediment was transferred to a microscope slide. A cover slip was applied to the drop. The slide was examined microscopically as described by Hendrix (1998).

Flotation technique

The procedure of flotation methods was as described by Hendrix (1998). 
Approximately $3 \mathrm{~g}$ of faeces was put in a beaker or a plastic container. Fifty milliliters of flotation fluid was poured to the beaker or a plastic container containing $3 \mathrm{~g}$ of faeces. The flotation fluid (sodium chloride) was mixed with faeces thoroughly with stirring device (tongue blade, fork). The resulting faecal suspension was poured through a tea strainer or double layer of cheesecloth into another beaker or plastic container. The faecal suspension was poured into a test tube from the second container, then placed in a test tube rack, leaving a convex meniscus at the top of the tube and a cover slip was carefully placed on top of test tube. The tube was left to stand for 15-20 minutes. The cover slip was lifted off from the tube vertically together with the drop of fluid adhering to it and immediately placed on microscope slide and examined under the microscope.

Microscopic examination of faeces for helminth eggs

This was done as described by Hendrix (1998). Compound microscope with the objective lens with a magnification power of $10 \mathrm{X}$ was first used to examine the prepared faecal smears. Mechanical microscopic stages were used for smooth and uniform movement of the slides. All the area under the cover slip was thoroughly and uniformly searched for the presence of parasitic eggs. When a parasite egg was observed at low magnification power (10X), high power object (40X) was used to examine it more closely and for the identified eggs. Bearman apparatus technique was used to identify the larvae of the helminthes, specially for $D$. arnfieldi.

Determination of eggs per gram of faec es (EPG)

A quantitative faecal examination was conducted using a modified McMaster egg counting technique to count helminth parasite eggs selectively on those samples positive for parasitic eggs upon qualitative procedure. A flotation fluid (sodium chloride) was used to separate eggs from faecal material in a counting chamber with two compartments. The procedures were done as described by Hansen and Perry (1994). Three grams of faeces were taken from the collected sample and 42 $\mathrm{ml}$ of water was added to it and emulsified using mortar and pestle. The solution was strained through a plastic tea strainer and the strained material was poured into $15 \mathrm{ml}$ centrifuge tube and centrifuged at $2000 \mathrm{rpm}$ for 2 minutes. Supernatant was poured off, sediment was agitated and the tube was filled to the previous level with flotation fluid (sodium chloride). Both sides of the McMaster counting chamber were filled with the subsample. The counting chamber was allowed to stand for 5 
minutes and the subsample in the counting chamber was examined under a compound microscope at $10 \mathrm{X}$ magnification power. All parasitic eggs within the engraved area of both chambers were counted and the number of eggs per gram of faeces (EPG) was calculated by adding the egg counts of the two chambers together and then multiplied the total by 50 .

Data analysis

Data collected from the study animals were coded and entered in a Microsoft Excel sheet. All statistical analyses were performed using SPSS version 16 for windows. The association between prevalence of each studied parasite and the study variables (season, age, sex, and BCS) was analyzed by Chi-square test of independence. Associations of total EPG with BCS were determined by Spearman test. One way ANOVA was used to observe the variations of total mean EPG of parasite species with age, season, and sex groups. In all the analyses, confidence level was held at $95 \%$ and $\mathrm{P}$-values $<0$. 05 were considered as significantly different.

\section{Results}

Prevalence of gastrointestinal helminthes in donkeys and mules

During the study period, faecal specimens taken from a total of 384 equines (212 donkeys and 172 mules) were thoroughly observed for the presence of different helminthic parasites. From the observed animals, 187 donkeys and 134 mules were positive for different helminthic parasites. In the study area, $5.88 \%$ of donkeys and $15.67 \%$ of mules harbored only one type of parasite (single infection) whereas $94.1 \%$ of donkeys and $84.33 \%$ of mules harbored two or more types of parasites (mixed infection). The overall prevalence of parasites in equines in the study area was found to be $83.59 \%$ (Table 1).

Table 1. Overall prevalence of gastrointestinal helminthes during the study period (October, 2010 to April, 2011) in equines (mules and donkeys)

\begin{tabular}{|c|c|c|c|c|}
\hline $\begin{array}{l}\text { Species } \\
\text { studied }\end{array}$ & $\begin{array}{l}\text { № of } \\
\text { animals } \\
\text { examined }\end{array}$ & $\begin{array}{l}\text { № of } \\
\text { positive } \\
\text { animals }\end{array}$ & Percentage & $\chi^{2}$ (p-value) \\
\hline Donkeys & 212 & 187 & 88.21 & \multirow{3}{*}{$7.346(0.007) *$} \\
\hline Mules & 172 & 134 & 77.91 & \\
\hline Total & 384 & 321 & 83 & \\
\hline
\end{tabular}


The parasites encountered in both donkeys and mules in the study period were strongyles $(65.09 \%$ in donkeys and $66.28 \%$ in mules), Trichostrongylus axei (42.45\% and 31.97\%), Triodontophorus (36.32\% and 33.72\%), Trichonema (34.91\% and $37.79 \%$ ), Parascaris equorum (13.68\% and $10.46 \%$ ), Dictyocaulus arnfieldi (22.17\% and 8.14\%), Anoplocephala (23.12\% and 16.86\%) and Fasciola species (17.92\% and 13.95\%), respectively (Figure 1).

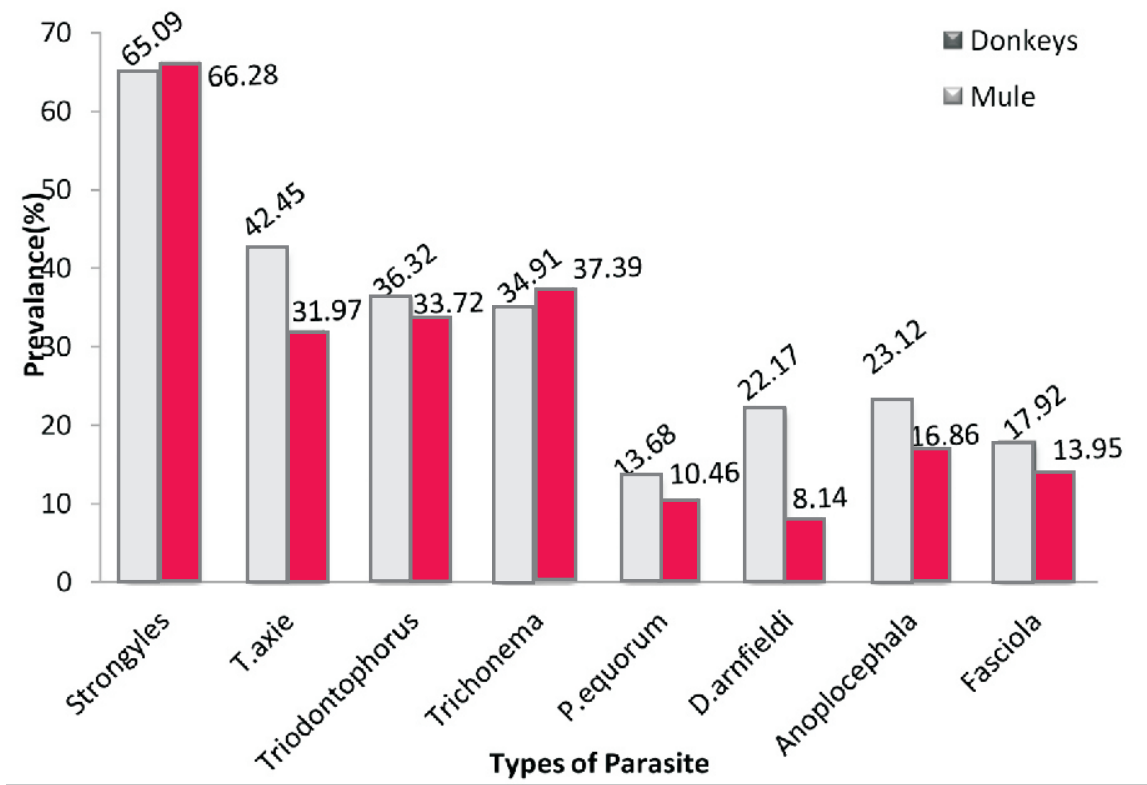

Figure 1. Types of gastrointestinal helminthes and their prevalence in donkeys and mules in the study period.

Age-wise comparison of studied animals for hosting one or more types of parasites showed varied prevalence. The prevalence of parasites was higher in old donkeys and mules than their young counterparts (Table 2). 
Table 2. Age-wise prevalence of different gastrointestinal helminthes in mules and donkeys

\begin{tabular}{|c|c|c|c|c|c|c|c|}
\hline \multirow{2}{*}{$\begin{array}{l}\text { Parasites } \\
\text { identified }\end{array}$} & \multicolumn{2}{|c|}{ Donkeys } & \multicolumn{5}{|c|}{ Mules } \\
\hline & $\begin{array}{l}\text { Young } \\
(\%)\end{array}$ & $\begin{array}{l}\text { Adult } \\
(\%)\end{array}$ & $\begin{array}{l}\text { Old } \\
(\%)\end{array}$ & $\chi^{2}$ (P-value) & $\begin{array}{l}\text { Adult } \\
(\%)\end{array}$ & $\begin{array}{l}\text { Old } \\
(\%)\end{array}$ & $\chi^{2}$ (P-value) \\
\hline Strongyles & 42.42 & 55.41 & 79.05 & $19.519(0.000)^{*}$ & 56.72 & 72.38 & $4.490(0.034)^{*}$ \\
\hline T. axei & 24.24 & 31.08 & 56.19 & $16.508(0.000)^{*}$ & 26.86 & 35.24 & $1.318(0.251)$ \\
\hline Triodontophorus & 15.15 & 32.43 & 45.71 & $10.884(0.004)^{*}$ & 23.88 & 40.00 & $4.755(0.0290)^{*}$ \\
\hline Trichonema & 18.18 & 31.08 & 42.85 & $7.460(0.024)^{*}$ & 25.37 & 45.71 & $7.199(0.007)^{*}$ \\
\hline P. equorum & 45.45 & 10.81 & 5.71 & $34.374(0.000)^{*}$ & 17.91 & 6.66 & $5.263(0.022)^{*}$ \\
\hline D. arnfieldi & 12.12 & 16.22 & 26.70 & $4.654(0.098)$ & 5.97 & 5.71 & $0.005(0.944)$ \\
\hline Anoplocephala & 12.12 & 20.27 & 28.57 & $4.340(0.114)$ & 11.94 & 20.00 & $1.895(0.169)$ \\
\hline Fasciola & 12.12 & 16.22 & 21.90 & $1.961(0.378)$ & 8.95 & 17.14 & $2.284(0.131)$ \\
\hline
\end{tabular}

* Statistically significant $(\mathrm{p}<0.05)$ among age groups of donkeys and mules

Comparison of the prevalence using sex of animals revealed the percentage prevalence of gastrointestinal helminthes to be higher in females than in males both in donkeys and mules. In donkeys, the prevalence of all identified parasites except Triodontophorus were statistically significant between the two sex groups $(\mathrm{P}<0.05)$. In contrast, all studied parasites were not statistically significant $(\mathrm{p}>0.05)$ between male and female mules (Table 3). 
Table 3. Sex-wise prevalence of different gastrointestinal helminthes in mules and donkeys

\begin{tabular}{|c|c|c|c|c|c|c|}
\hline \multirow[t]{2}{*}{ Parasite identified } & \multicolumn{3}{|c|}{ Donkeys } & \multicolumn{3}{|l|}{ Mules } \\
\hline & Male (\%) & $\begin{array}{l}\text { Female } \\
(\%)\end{array}$ & $\chi^{2}$ (P value) & Male (\%) & Female (\%) & $\chi^{2}$ (P value) \\
\hline Strongyles & 55.35 & 76 & $9.908(0.002)^{*}$ & 65.00 & 67.39 & $0.109(0.741)$ \\
\hline T. axei & 35.71 & 50 & $4.413(0.036)^{*}$ & 31.25 & 32.61 & $0.036(0.849)$ \\
\hline Triodontophorus & 48.21 & 43 & $3.651(0.056)$ & 32.50 & 34.78 & $0.100(0.752)$ \\
\hline Trichonema & 27.68 & 43 & $5.458(0.019)^{*}$ & 33.75 & 41.30 & $1.039(0.308)$ \\
\hline P. equorum & 8.92 & 19 & $4.538\left(0.033^{*}\right.$ & 10.00 & 10.87 & $0.035(0.853)$ \\
\hline D. arnfieldi & 15.18 & 30.00 & $6.726(0.010)^{*}$ & 7.50 & 8.70 & $0.082(0.775)$ \\
\hline Anoplocephala & 16.07 & 31 & $6.625(0.010)^{*}$ & 15.00 & 18.48 & $0.369(0.543)$ \\
\hline Fasciola & 12.5 & 24.00 & $4.749(0.029)^{*}$ & 11.25 & 16.30 & $0.910(0.340)$ \\
\hline
\end{tabular}

*Statistically significant $(p<0.05)$ between sexes of donkeys and that of mules In relation to $\mathrm{BCS}$, the percentage prevalence of helminthic parasites was higher in animals with poor BCS and medium than animals with good BCS (Table 4). 
Table 4. Percentage prevalence of gastrointestinal helminthes based on BCS in mules and donkeys

\begin{tabular}{|c|c|c|c|c|c|c|c|c|}
\hline \multirow[t]{2}{*}{ Parasites identified } & \multicolumn{4}{|c|}{ Donkeys } & \multicolumn{4}{|l|}{ Mules } \\
\hline & $\begin{array}{l}\text { Poor } \\
(\%)\end{array}$ & $\begin{array}{l}\text { Medium } \\
(\%)\end{array}$ & $\begin{array}{l}\text { Good } \\
(\%)\end{array}$ & $\chi^{2}$ (P value) & $\begin{array}{l}\text { Poor } \\
(\%)\end{array}$ & $\begin{array}{l}\text { Medium } \\
(\%)\end{array}$ & $\begin{array}{l}\text { Good } \\
(\%)\end{array}$ & $\chi(\mathrm{P}$ value $)$ \\
\hline Strongyles & 80.00 & 64.81 & 54.23 & $7.465(0.024)^{*}$ & 85.71 & 67.36 & 47.62 & $12.509(0.002)^{*}$ \\
\hline T. axei & 75.60 & 41.70 & 18.64 & $33.901(0.000)^{*}$ & 57.14 & 31.57 & 11.90 & $17.977(0.000)^{*}$ \\
\hline Triodontophorus & 73.33 & 33.33 & 13.56 & $40.286(0.000)^{*}$ & 51.42 & 29.47 & 28.57 & $6.175(0.046)^{*}$ \\
\hline Trichonema & 62.22 & 31.48 & 20.33 & $20.845(0.000)^{*}$ & 74.28 & 34.73 & 14.28 & $30.076(0.000)^{*}$ \\
\hline P. equorum & 35.56 & 9.25 & 6.77 & $21.737(0.000)^{*}$ & 22.87 & 10.52 & 0.00 & $10.646(0.005)^{*}$ \\
\hline D. arnfieldi & 51.11 & 17.59 & 10.17 & $27.635(0.000)^{*}$ & 28.57 & 3.15 & 3.80 & $24.557(0.000)^{*}$ \\
\hline Anoplocephala & 55.56 & 17.59 & 8.47 & $35.618(0.000)^{*}$ & 40.00 & 9.47 & 9.52 & $19.611(0.000)^{*}$ \\
\hline Fasciola & 40.00 & 15.74 & 5.08 & $21.868(0.000)^{*}$ & 37.14 & 11.57 & 0.00 & $22.933(0.000)^{*}$ \\
\hline
\end{tabular}

*Statistically significant $(\mathrm{p}<0.05)$ among BCS groups of donkeys and mules

Intensity of infection in donkeys and mules

Based on the results of EPG counts in the study area, $46.82 \%$ donkeys were severely infected, $86.31 \%$ moderately, and $69.47 \%$ mildly whereas $39.42 \%$ mules were infected severely, $93.43 \%$ moderately, and $80.29 \%$ mildly (Figure 2 ). 


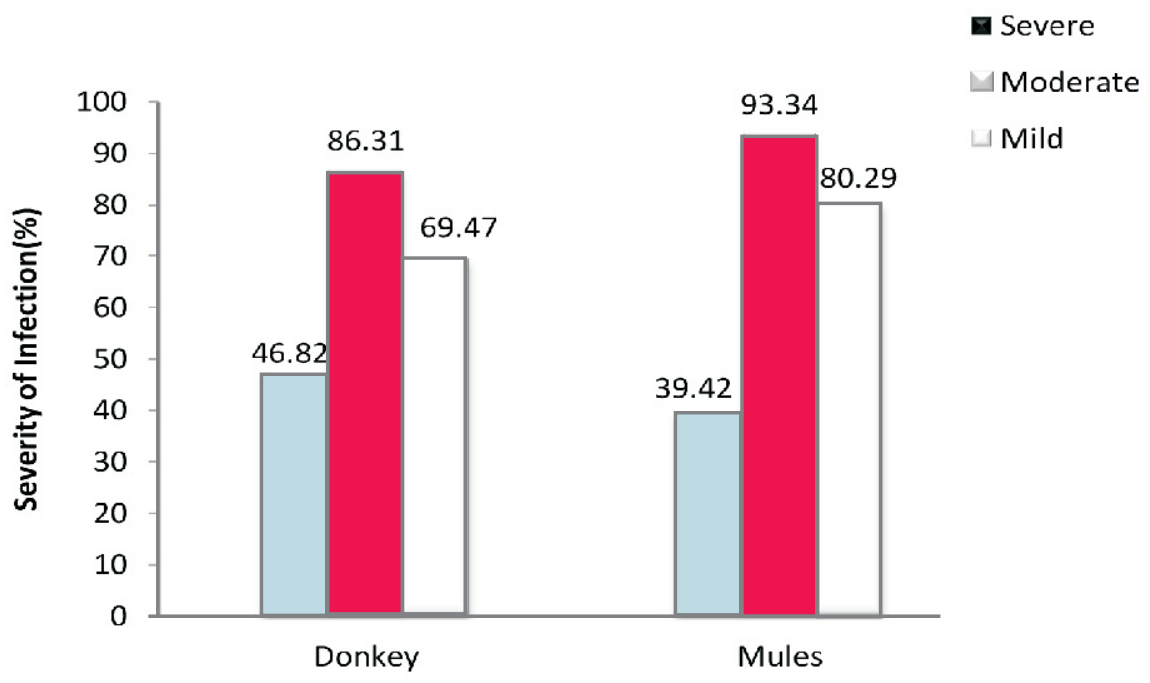

Animals Studied

Figure 2. Overall severity of infection by nematode helminthes in donkeys and mules

Total mean EPG counts of major nematode parasites in relation with sex and age groups were analyzed and shown in tables (5-8) for both donkeys and mules. Body condition score was negatively correlated $(\mathrm{r}=-0.664$ for donkeys and $\mathrm{r}=-0.637$ for mules) with total EPG counts.

Table 5. Mean value $\pm \mathrm{SD}$ of EPG in different sexes of donkeys for different parasites

\begin{tabular}{lccc}
\hline \multirow{2}{*}{$\begin{array}{l}\text { Parasites } \\
\text { identified }\end{array}$} & \multicolumn{3}{l}{ Donkeys } \\
\cline { 2 - 4 } & Male & Female & P-value \\
\hline Strongyles & $644.35 \pm 496.31$ & $1051.30 \pm 506.81$ & $0.000^{*}$ \\
T. axei & $626.25 \pm 573.78$ & $1006.00 \pm 507.76$ & $0.001^{*}$ \\
Triodontophorus & $614.71 \pm 552.34$ & $1014.00 \pm 552.08$ & $0.002^{*}$ \\
Trichonema & $827.42 \pm 611.26$ & $881.40 \pm 454.08$ & 0.664 \\
\hline
\end{tabular}

*Statistically significant $(\mathrm{p}<0.05)$ between the two sexes 
Table 6. Mean value \pm SD of EPG in different sexes of mules for different parasites

\begin{tabular}{lclc}
\hline Parasites identified & \multicolumn{2}{c}{ Mules } \\
\cline { 2 - 4 } & \multicolumn{1}{c}{ Male } & Female & p-value \\
\hline Strongyles & $464.42 \pm 99.06$ & $940.32 \pm 527.04$ & $0.000^{*}$ \\
T. axei & $550.00 \pm 484.98$ & $1033.00 \pm 538.90$ & $0.001^{*}$ \\
Triodontophorus & $465.38 \pm 488.62$ & $673.44 \pm 538.06$ & 0.133 \\
Trichonema & $509.26 \pm 536.02$ & $976.32 \pm 506.27$ & $0.001^{*}$
\end{tabular}

*Statistically significant $(\mathrm{p}<0.05)$ between male and female mules

Table 7. Mean value \pm SD of EPG in different age groups for different parasites in donkeys

\begin{tabular}{lllll}
\hline $\begin{array}{l}\text { Parasites } \\
\text { Identified }\end{array}$ & \multicolumn{4}{c}{ Age groups } \\
\cline { 2 - 5 } & Young & Adult & Old & P-value \\
& & & & \\
& & & & \\
\hline Strongyles & $910.71 \pm 689.53$ & $600.00 \pm 461.52$ & $995.18 \pm 506.94$ & $0.000^{*}$ \\
T. axei & $293.75 \pm 232.13$ & $539.13 \pm 465.63$ & $1028.1 \pm 542.46$ & $0.000^{*}$ \\
Triodontophorus & $390.00 \pm 108.39$ & $481.25 \pm 529.52$ & $1069.80 \pm 529.22$ & $0.00^{*}$ \\
Trichonema & $475.00 \pm 434.45$ & $634.78 \pm 622.57$ & $1026.70 \pm 400.35$ & $0.002^{*}$ \\
& & & & \\
\hline
\end{tabular}

*Statistically significant $(\mathrm{p}<0.05)$ among age groups 
Table 8. Mean value \pm SD of EPG in different age groups for different parasites in mules

\begin{tabular}{lccc}
\hline Parasites & \multicolumn{3}{c}{ Age groups } \\
\cline { 2 - 4 } identified & Adult & Old & P-value \\
\hline Strongyles & $388.16 \pm 301.89$ & $913.82 \pm 543.05$ & $0.000^{*}$ \\
T. strongylus & $488.89 \pm 382.93$ & $971.62 \pm 577.61$ & $0.002^{*}$ \\
T. dontophorus & $243.75 \pm 218.99$ & $729.76 \pm 541.91$ & $0.001^{*}$ \\
& & & \\
Trichonema & $405.88 \pm 286.62$ & $942.71 \pm 573.53$ & $0.000^{*}$ \\
& & & \\
\hline
\end{tabular}

\section{Discussion}

The prevalence of gastrointestinal helminthes may vary temporally and spatially. The results of the present study demonstrated the presence of 8 different types of helminthic parasites in donkeys and mules in and around Bahir Bar. The overall prevalence of different helminthic parasites was found to be $88.21 \%$ and $77.91 \%$ in donkeys and mules, respectively. The prevalence was significantly higher in donkeys $(p<0.05)$ than in mules. This might be associated with negligence; donkeys were given less attention by their owners and were kept under poor management conditions than their counterparts, mules (personal communication with the owners of equines) and mules may have higher resistance than donkeys. The occurrence of 8 types of helminthic parasites in different percentage in the study area might also be associated with (1) suitable humidity and moisture provided by warm and wet conditions throughout the year for the eggs to develop to larval stage $\left(\mathrm{L}_{3}\right)$ (Andrews, 1999); (2) temperature that was favorable for the development and maturation of the larvae of the most helminthic species (Lima et al., 1990), and (3) ample provision of water that facilitated the migration of larvae from manure to the herbage (Lima, 1998) and development and multiplication of snails in case of the transmission of Fasciola species; as well as poor management system, for example lack of antihelmenthic treatment, over working time and allowing the equines for open grazing after work which facilitates ingestion of the eggs of helminthes in the study area (personal communication). 
The finding of the current study was in line with the previous reports in other countries. Mattioli et al. (1994), Paudel (2007) and Umur and Acici (2009) have reported $84.4 \%, 80.48 \%$ and $93.5 \%$ prevalence of parasites in equines of Gambia, Nepal and Turkey, respectively. The current finding, however, was lower than other findings reported by other workers in Ethiopia. Yosef Shiferaw et al. (2001), Fikru Regassa et al. (2005), Mulate (2005), and Ayele Gizachew et al. (2006) have reported the prevalence of helminthic parasites to be $100 \%, 100 \%, 98.2 \%$ and $100 \%$ in donkeys of Wonchi, Highlands of Wollo provine, Western highlands of Oromia, and Dugda Bora district, respectively. The relative low occurrence of helminthic parasites in Bahir Dar might be associated with the agro-ecological differences, veterinary services provided by Bahir Dar Regional Veterinary clinic for equines and the diagnostic capacity of the parasitological technique used.

Varied prevalences, which ranged from $8.14 \%$ to $66.28 \%$, were observed in equines during the study period. Among the eight different types of helminthic parasites identified in the current study, strongyles $(65.09 \%$ in donkeys and $66.28 \%$ in mules) were found to be dominant in the study area. This was in agreement with the finding of Ayele Gizachew et al. (2006) who reported 100\% prevalence of strongyles in donkeys of Dugda Bora. In our study, the second most prevalent helminth in donkeys next to strongyles was T. axei (42.45\%) followed by Triodontophorus (36.32\%), Trichonema (34.91\%), Anoplocephala (23.12\%), D. arnfieldi (22.17\%), Fasciola (17.92\%), and, P. equorum (13.86\%) whereas the second most prevalent helminth in mules was Trichonema $(37.79 \%)$ followed by Triodontophorus (33.72\%), T. axei (31.97\%), Anoplocephala (16.86\%), Fasciola $(13.95 \%)$, P. equorum (10.46\%), and D. arnfieldi $(8.14 \%)$. The prevalence of the top three gastrointestinal parasites, strongyles, T. axei, and Triodontophorus of donkeys, for instance, are in agreement, respectively, with the prevalence of $92 \%$, $12 \%$, and $29.7 \%$ in donkeys of central Shoa, Ethiopia (Ayele Gizachew and Dinka Ayana, 2010), and in donkeys of Hawassa and its surrounding (Nuraddis Ibrahim et al., 2011).

Female donkeys were found to have significantly higher infestation of strongyles than their counterpart males as they might have lower immunity due to gestation, lactation and stresses occurred during this period (Sapkota, 2009). However, no significant difference was observed between the two sexes of mules. This might be due to the absence of gestation and lactation in the female mules. Generally, it is assumed that sex is a determinant factor that influences the prevalence of parasitism (Pal and Qayyum, 1992). 
The highest prevalence of strongyles infestation was seen in animals of old age in both donkeys and mules than in their young. This finding disagrees with the work of Niredin et al. (2011), Ayele Gizachew and Dinka Ayana (2010) in Hawassa and its surrounding and central Shoa, Ethiopia, respectively. But, it was in agreement with the work of Sapkota, 2009. The probable reason may be due to waning body conditions and immunity. Compared to the young equines, the immunity of the old equines is low as they are frequently exposed to different parasites, extensive work overload, and undernourished conditions (Sapkota, 2009).

The body condition score was negatively correlated ( $\mathrm{r}=-0.664$ for donkeys and $\mathrm{r}=$ 0.637 for mules) with the total EPG counts, implying equines with poor BCS are good indicators of parasitic burden which can be used by the resources limited communities to identify donkeys and mules with immediate requirements of anthelmintic remedies. This finding was in agreement with the findings of Ayele Gizachew et al. (2006) who reported the value of $r$ as -0.67 in donkeys of Dugda Bora district and the relation was significantly higher. For instance, the prevalence of strongyles was higher in animals of poor BCS than good BCS in both donkeys and mules. The reason might be associated with the fact that animals with poor BCS have waning immunity and as a result they could not resist the parasites burden when compared with animals of good BCS (Sapkota, 2009).

In the current study the mean EPG count of nematode helminthes was found to be 838.09 and 710.05 in donkeys and mules, respectively. The finding was lower than the previous studies conducted by Seri et al. (2004) in Sudan and Ayele Gizachew and Dinka Ayana (2010) in Ethiopia who reported mean EPG count of 1016.6 and 2893 , respectively. The difference might be associated with geographical variation and climatic factors. A high seasonal variation in the eggs per gram of faeces (EPG) of donkeys and mules was observed, the highest being in the wet season (896.48) and the lowest in the dry season (779.7) in donkeys and 815.72 and 605.9 in mules in wet and dry seasons, respectively. This might be associated with suitable weather conditions for development of parasitic larvae.

\section{Conclusion}

Equines have crucial importance in the livelihood of developing countries especially in Africa, particularly for transportation. In this study, 8 types of helminthic parasites (strongyles, T. axei, Triodontophorus, Trichonema, P. equorum, D. arnfieldi, Anoplocephala, Fasciola) were found both in donkeys and mules with an overall prevalence of $83.59 \%$. This prevalence was relatively high; 
$46.82 \%$ of donkeys and $39.42 \%$ of mules were severely affected. Owners of equines should be educated about proper management of equines such as providing sufficient food and shelter, minimizing overworking and extensive open grazing.

\section{Acknowledgements}

The authors would like to thank Biology Department, Bahir Dar University, and Bahir Dar Regional Veterinary Laboratory for allowing us to use their facilities.

\section{References}

Andrews, S. J., 1999. The life cycle of Fasciola hepatica. In: Dalton, J.P. (Ed.), Fasciolosis. CABI Publishing, Walling Ford, UK. pp. 1-30.

Crane, M. and Sevendsen, E., 1997. The professional handbook of the donkey, $3^{\text {rd }}$ edition, White book LTD, London, p. 29.

Fielding, D., 1991. Horses, Donkeys and Mules in Tropical Agricultural Development, $3^{\text {rd }}$ edition, University of Edin burgh. pp. 140-145.

Gebreab, F., 1998. Proceeding of international conference on equines infectious diseases held in Dubi, United Arab Emirate.

Gebreab, F., Mohammed, A. and Jobre, Y., 1991. Vermicular endoparasitism in donkeys of Debre Zeit and Menagesha, Ethiopia. Donkeys, mules and horses in tropical agricultural development. In: Proceedings Colloquium on Donkeys, Mules and Horses, (Fielding, D. and Pearson, R.A. (Eds.), University of Edinburgh, Center for Tropical Veterinary Medicine, UK. pp. 156-166.

Gizachew, A., Gebreab, F., Endebu, B., and Joe, A., 2006. Prevalence of gastrointestinal parasites of donkeys in Dugda Bora District, Ethiopia. Livest. Res. Rural Dev., 18 (10):1-11 .

Gizachew, A. and Ayana, D., 2010. Study on Strongyles and Parascaris parasites population in working donkeys of centeral Shoa, Ethiopia. Livest. Res. Rural Dev., 22 (12): 1-5.

Hansen, J. and Perry, B., 1994. The Epidemiology, Diagnosis and Control of Helminthic Parasites of Ruminants. ILRAD, Nairobi, Kenya. pp. 73-81.

Hendrix, C., 1998. Diagnostic Veterinary Parasitology, $2^{\text {nd }}$ edition, Mosby.

Http://campus.Iss.nl (accessed on 17.02.2011) 
Ibrahim, N., Berhanu, T., Deressa, B. and Tolosa, T., 2011. Survey of prevalence of helminth parasites of donkeys in and around Hawassa town, southern Ethiopia. Glob., Vet., 6, 223-227.

Krecek, R., Reinecke, R. and Horak, I., 1989. Internal parasites of horses on mixed Grassveld and Bushveled in Transveal, Republic of South Africa. Vet. Parasitol., 34, 135-145.

Lima, J. D., Lima, W. S., Guimaraes, A. M., 1990. Epidemiology of bovine nematode parasites in Southeastern Brasil. In : Proceedings, MSD., AGUET symposium, (Guerrero, J., Leaning, W.H.D. (Eds.), Epidemiology of Bovine Nematode Parasites in Americas., Bahia Brasil. pp. 49-63.

Lima, W. S., 1998. Seasonal infection pattern of gastrointestinal nematodes of beef cattle in Minas Grais state, Brasil. Vet. Parasitol., 74, 203-214.

Mattioli, R. C., Zinsstag, J. and Pfister, K., 1994. Frequency of trypanosomosis and gastrointestinal parasites in draught donkeys in the Gambia in relation to animal husbandry. Trop. Anim. Hlth. Prod., 26, 102-108.

Marquardt, W. C., Demaree, R. S. and Grieve, R. B., 2000. Parasitology and Vector Biology, $2^{\text {nd }}$

edition, Harcourt Academic Press, London, pp. 381-385.

Mulate, B., 2005. Preliminary study on helminthosis of equines in south and north Wollo Zones. Ethiop. Vet. J., 9, 25-37.

Pal, R. A. and Qayyum, M., 1992. Breed, age and sex wise distribution of helminthes of sheep and goats in and around Rawalpidi region. Pak. Vet. J., 12, 60-63.

Pandit, B. A., Shahardar, R.A. and Jalabal, L., 2008. Prevalence of GI parasitic infections in equines of Kashimir Valley. Vet Scan, 3, 1-4.

Paudel, S., 2007. Prevalence of gastrointestinal parasites in horses with special reference to Strongylus species of Sainik Stud Farm Center Bharatpur, Chitwan. Blue Cross Annu Bull. NVSA, 9, 104-105.

Regassa, F., Reta, D. and Mideksa, B., 2005. Prevalence of equines gastrointestinal parasites in western highlands of Oromia, Ethiopia. Bull. Anim. Hlth. Prod. Afr., 53, 161-166.

Sapkota, C. R., 2009. A report on prevalence of helminthes parasites in mules of Brick Kiln of

Lalitpur District. Himalayan College of Agricultural Sciences and Technology. Purbanchal University Gatthaghar, Bhaktapur. 
Seri, H. I., Hassan, T., Salih, M. M., and Abakar, A. D., 2004. A survey of gastrointestinal nematodes or donkeys (Equus asinus) in Khartoum State. J. Anim.Vet. Adv., 3, 736739.

Shiferaw,Y., Gebreab, F. and Wossene, A., 2001. Survey on helminthosis of equines in Wonchi, Ethiopia. Ethiop. Vet. J., 5, 49-67.

Soulsby, E. J. L., 1982. Helminthes, Arthropods and Protozoa of Domesticated Animals, $7^{\text {th }}$ edition, Bailliere,Tindall, London, pp. 650-700.

Svendsen, E. D., 1986. The professional handbook of donkeys, sovereign printing group, England. Pp. 77-78.

Svendsen, E. D., 1997. Parasites abroad. The professional handbook of the donkey, 3 rd edition. Whittet Books Limited, London, pp.166-182.

Tegegne, A. and Crawford, W., 2000. Draft animal power use in Ethiopia. In: Draft animal news, No.33, December 2000. Center for Tropical Veterinary Medicine.

Thrusfield, M., 1995. Veterinary Epidemiology, $2^{\text {nd }}$ edition, Blackwell Wissenchafts Verlag, erlin. Umur, S. and Acici, M., 2009. A survey on helminth infection of equines in the central Black sea region, Turkey. Turk. J. Vet. Sci., 33, 373-379.

Urquhart, G. M, Armour, J., Duncan, J. L and Jennings, F. W., 1996. Veterinary Parasitology, $2^{\text {nd }}$ edition, Blackwell Science, pp. 42-47.

Wilson, R. T., 1991. Equines in Ethiopia. In: Fielding, D., Pearson, R. A. (Eds.), Donkeys, mules and horses in tropical agricultural development (Proceedings of a colloquium held 3-6 September 1990, Edinburgh, Scotland. Centre for Tropical Veterinary Medicine, University of Edinburgh pp. 33-47.

Wilson, R. T., (2002). Specific welfare problems associated with working horses. In: Waran, N. (Ed.), The welfare of horses. Kluwer Academic Publishers, Dordrecht, pp. 203218. www.esgpip.org/Amhara.htm (accessed on 20/04/2011). 